\title{
Olhares portugueses sobre o Magrebe: mitos e realidades
}

\author{
Jorge Afonso*
}

\begin{abstract}
Resumo
Este artigo, abordando fontes dos Séculos XVIII, XIX e XX, faz uma breve incursão ao estudo da leitura que vigorou em Portugal do Islão magrebino. Relatos de cativeiro em Banhos magrebinos versus produções ideológicas dadas à estampa em Portugal, justificativas da incompreensão de um outro civilizacional que se continuava a desvalorizar, mesmo quando ele era fundamental à saúde estratégica do Estado, são elementos de uma ampla realidade bem diferente daquela transmitida à opinião pública portuguesa. Ao mito vigente, opunha-se a imagem de um Islão abrangente e inclusivo, mais propenso à tolerância que alguns dos seus êmulos da margem norte do Mediterrâneo.
\end{abstract}

Palavras-chave: Cativos; Corso; Islão; Magrebe; Judeus.

O conceito estratégico de Magrebe lançou raízes no pensamento político e diplomático português, no último quartel do Século XVIII e primeiro decênio do XIX. Quando, em 5 de setembro de 1769, o xarife ${ }^{1}$ de Marrocos escreveu ao rei D. José, três meses após o abandono de Mazagão, no sentido de transformar a trégua existente em Tratado definitivo de Paz, Navegação e Comércio, a diplomacia portuguesa dava início a um longo processo de complementaridade estratégica que terminaria no acordo com a regência de Argel em 1813. Pelo meio ficavam outros estabelecidos com as regências de Tripoli e Tunes a seu tempo dados à estampa na Gazeta de Lisboa.

O conjunto mais vasto do território composto pelas regências magrebinas e o império alauita sobrepunha-se à importância destas realidades políticas consideradas individualmente para o reino português. A dimensão atlântica e a segurança do seu tráfego, aliada aos novos dados da conjuntura europeia, motivaram que ao espaço

\footnotetext{
* Pesquisador do Instituto de Cultura Ibero-Atlântica, Mestre em História dos Descobrimentos e da Expansão pela Faculdade de Letras de Lisboa (FLL), doutorando na mesma área na FLL.

${ }^{1}$ Título dos príncipes mouros decendentes de Maomé; título de autoridade muçulmano.
} 
marroquino, então tradicionalmente de importância crucial para as opções geoestratégicas de Portugal, se adicionasse outro designado por Magrebe.

A atitude empreendida por numerosos autores europeus que olharam o oriente muçulmano com um misto de fraternidade e compreensão, tendo o seu fundamento no igualitarismo e bondade natural do homem, verdadeira religião da época, permitindo, assim, rever críticas antigas ao mundo islâmico, não teve correspondente no reino português.

A última metade do Século XVIII revelou-nos algumas traduções de obras publicadas na França de autoria de viajantes europeus que cruzaram o espaço magrebino, bem assim, como várias outras cujo impacto foi relevante para a formulação do pensamento político e geoestratégico de finais do Século XVIII e princípios do XIX.

Aos relatos impressos teremos, obrigatoriamente, de juntar a correspondência e outros escritos diplomáticos, oriundos dos mais variados pontos do Magrebe, descrições de cativeiro dos marinheiros portugueses na regência de Argel e as introduções às longas listas de cativos resgatados em Argel e Mequinez pelos Padres Redemptores da Santíssima Trindade da Província de Portugal.

Segundo Maxime Rodinson (1989), o Século XIX traz consigo as três tendências combinadas do ocidentalismo pragmático e imperialista, pleno de desprezo por outras civilizações, de exotismo romântico deslumbrado pelo Oriente cuja crescente pobreza realça o charme da erudição especializada, ligadas ao estudo de épocas passadas. As características que este autor aponta ao Século XIX europeu não se aplicam ao espaço português e, para o constatar, nada mais necessário do que analisar alguns dos textos fundadores da forma de ler o Islão magrebino produzidos neste período em Portugal.

Em pleno Século XVIII, o conhecimento da língua árabe era uma condição fundamental para extravasar competências da área filológica para o âmbito mais alargado do aconselhamento e acompanhamento das variadas missões diplomáticas portuguesas que rumaram ao espaço magrebino. Dos arabistas Fr. João de Sousa, Fr. José de Santo António Moura e Fr. Manuel Rebelo da Silva, herdamos para além das suas obras de experimentados tradutores, documentos de fina análise diplomática. Epocalmente marcados, credores da tentativa de prolongar uma supremacia ao arrepio da ideologia do seu tempo que a Europa do Século XIX se preparava para implementar, em todo o Norte de África, os escritos dos arabistas portugueses, juntamente com outros, são ensaios vãos de manutenção de influência no espaço magrebino que a conjuntura internacional da época já não conseguia sustentar. 
Digamos, em abono da verdade, que só a visão de uma dinastia de diplomatas, os Colaço, conseguiu manter em bases aceitáveis e exequíveis as relações com o império alauita que, depois, estrategicamente, acabariam por se estender ao resto do conjunto magrebino. Geriram os Colaço toda esta complexa teia de interesses diplomáticos usando, para além da necessária racionalidade, pragmatismo e conhecimento do terreno em que se moviam, de uma dose, muito acentuada, de afetividade e bom senso, características fundamentais nas relações com o Islão neste particular espaço geográfico.

Em outubro de 1780, num extenso documento intitulado Reflexão sobre as vantagens de um Tratado de Paz com Argel (ARQUIVO HISTÓRICO ULTRAMARINO, [1790?]), discorria-se sobre o proveito que o Reino poderia vir a usufruir de um possível acordo com a Regência. Para além da análise das inevitáveis vantagens comerciais e estratégicas, com o enumerar de benefícios e custos, sendo os primeiros consideravelmente maiores do que os segundos, partia-se para a caracterização do seu espaço político:

\begin{abstract}
De todos os Estados da Barbaria, he Argel o mais importante para os européos, sendo que os seus súbditos são os mais belicozos, e tão inclinados ao côrso, que se póde chamar este, o seu principal commercio, e ramo que lhes dá muitas riquezas, tanto pelas prezas de embarcaçoens, e cargas, como pela de escravos que nestas captivão, e que lhes atraem immensas sommas de dinheiro nos seus resgates, de sórte que não sómente o governo,mas também os particulares tem os seus corsarios, reputando-o como hum commercio lucrativo, hé para elles o quinto dos escravos, que o governo toma para sy. Por este motivo costumam estar quazi sempre em guerra com as naçõens que confinão com o Mediterrâneo, como são, a Hespanha, Genova, Toscana,etc.etc. as quaes pela sua situação se vem obrigadas a vêr as suas andeiras expostas a insultos; tambem de tempos em tempos rompem com alguns Estados do Norte; porem estes costumão procurar, e manter a páz com elles à força de regálos, bem convencidos das grandes vantagens que lhes rezultão, de terem o seu commercio, e navegação livres no Mediterraneo; e conhecendo pela experiencia, só o resgate da sua gente lhes custará mais que os regálos que lhes dão. (ARQUIVO HISTÓRICO ULTRAMARINO, [1790?]).
\end{abstract}

Essa longa reflexão sobre uma das principais atividades da Regência, diretamente ligada à sua marinha de guerra armada em corso, ela própria abordada em obras literárias circulando no Reino e ideologicamente comprometidas com o movimento de redenção de cativos, é elucidativa de uma visão muito particular do Islão magrebino, contrariando as ideias então ainda em circulação no espaço europeu.

Em outro documento, este já datado de um período que se pode calcular entre 1790 e 1792, fazem-se referências ao caráter do sultão alauita Mawlay Yazid (1790- 
1792), monarca, considerado pelo seu autor, portador de um ânimo generoso, soberbo e violento nas suas resoluções (ARQUIVO HISTÓRICO ULTRAMARINO, [179-]). É na sequência desta importante fonte que reputamos de fundamental para o estudo das relações com o império xarifino no âmbito mais alargado do Magrebe, que tem lugar uma questão na qual o pragmatismo e a afetividade se sobrepõem aos preconceitos de índole religiosa e suposta superioridade civilizacional.

A rebelião que teve lugar em Marrocos, logo após a morte de Mawlay Yazid, fez dos principais portos ligados à exportação de trigo, locais estratégicos à volta dos quais se teceram uma intrincada rede de interesses e onde a oposição a Mawlay Sulayman tentou colher vastos proveitos. A ofensiva diplomática encetada em direção à Europa por Mawlay Hisham, um dos pretendentes, teve também Portugal como alvo.

Em julho de 1793, o governador de Salé escreveu a Martinho de Melo e Castro, ministro da rainha de Portugal D. Maria I, oferecendo a livre frequência dos portos marroquinos da Costa Atlântica sob o seu domínio aos comerciantes portugueses que aí geralmente se dirigiam para escoar a produção das férteis planícies marroquinas. $\mathrm{O}$ ministro português recusou a ingerência nos assuntos internos do Islão marroquino e foi mais longe ao admoestar o proponente de tal ideia, acrescentando mesmo que proibiria qualquer vassalo português de frequentar lugares rebelados contra o seu legítimo sultão (ARQUIVO HISTÓRICO ULTRAMARINO, [179-]).

Em fevereiro de 1796, o pretendente ao trono deixado vago pela morte de Mawlay Yazid, Mawlay Hisham, enviou um embaixador à corte portuguesa. Apostava este príncipe alauita num dos bens mais valiosos que tinha para oferecer, esperançado que a já crônica necessidade portuguesa em matéria de trigo lhe proporcionasse o reconhecimento. Puro engano, o príncipe regente não só não o fez como também não aceitou o enviado marroquino como "Embaixador Público". Amenizou contudo um pouco a sua resposta em relação à carta expedida por Martinho de Melo e Castro ao governador da Duquela. D. João ofereceu-se para “[...] contribuir com os nossos bons officios para que a boa harmonia se restabeleça entre vos e os principes vossos irmaons, de maneira que a liberdade de commercio não sofra impedimentos." (ARQUIVO HISTÓRICO ULTRAMARINO, 1796). O pragmatismo português e o relativo papel secundário do Reino no concerto das potências europeias levavam a que os remanescentes e anacrônicos conceitos em relação ao Islão magrebino fossem temporariamente relegados para segundo plano, face à conjuntura interna e externa na qual Portugal se encontrava inserido. 
Em março de 1814, já com a assunção plena da totalidade magrebina por parte das autoridades em Lisboa e no Rio de Janeiro, na sequência da assinatura do Tratado de 1813 com a regência de Argel, foi emitido um documento de capital importância para as relações luso-magrebinas. O conhecimento que o arabista português Fr. Manuel Rebelo da Silva, da incontornável "escola" de tradutores do Convento de Nossa Senhora de Jesus, manifestava sobre os negócios de Marrocos, levou-o a produzir um importante conselho a pedido de D. Miguel Pereira Forjaz. Este foi escrito para “[...] responder ás perguntas que V.Exa. se dignou fazer-me para deliberar com mais conhecimento, acerto, e segurança possivel nos Negocios com Marrocos.” (ARQUIVO HISTÓRICO ULTRAMARINO, 1814). Terá de se esperar pelo final do Século XIX e pela polêmica substituição do último dos Colaço, à frente da legação portuguesa em Tânger pelo conde de Martens Ferrão, para as questões do Islão magrebino serem definitivamente entregues a especialistas laicos.

A leitura dos relatos de cativeiro nos quais se inserem aqueles relativos às descrições das condições de vida nos Banhos das regências, é fundamental para a constituição da imagem do Islão em vigor no reino português relativamente ao Magrebe. Esta é afetada por três ideias constituintes da forma de pensar europeia ao longo da sua história, centradas à volta de um eixo constituído pelo Mare Nostrum: o medo do Islão; a ostracização do judeu; a diabolização da mulher. A elas podemos juntar, em finais de setecentos e inícios de oitocentos, o confronto entre a ideologia do Antigo Regime e os novos conceitos originários da nascente Revolução Francesa que eclodiu entre a elite dos cativos portugueses então em Argel.

O sentimento de medo face ao Islão que atravessou toda a sociedade europeia entre os Séculos XVI e XIX e que também atingiu, tendo em atenção as suas especificidades muito próprias, a portuguesa tem um dos seus paradigmas na odisseia de Simão Gonçalves (BENASSAR, 2006, p. 43-62). Nascido em Ceuta e educado em Lagos este português é um acabado produto do Estreito, da junção das águas do Mare Nostrum com o Grande Oceano, local mítico que passaria grande parte da sua vida a franquear no encontro de três tipos de fronteira entre o Islão e a Cristandade: a geográfica; a militar; a religiosa.

Mas quem é, no fundo, Simão Gonçalves e qual o seu impacto na imagem do Islão percebida em Portugal? Quanto a nós, o contrário de tudo aquilo que a literatura apologética, de viagens e os relatos de cativeiro dos Séculos XVIII e XIX tentaram inculcar na opinião pública portuguesa da época. Homem de confiança do seu senhor, 
possuidor de cativos cristãos como recompensa de bons serviços prestados ao Islão, irá, contudo, cometer um nefando pecado. Em terra de mouros, onde não existia casamento ou pronúncia de palavras sacramentais, confessou ter conhecido carnalmente várias mulheres e projetado o ajuntamento com uma infiel. Indiferente à cor e ao gênero do parceiro, detentor de uma legítima mulher no Reino, várias outras no Magrebe, não desdenhando a companhia de rapazes que várias testemunhas o viram bastas vezes acariciar, Simão Gonçalves representava, juntamente com o fantasma do perigo islâmico, um dos mais importantes medos do ideário medieval europeu. Sentimento transportado para o Séc. XVI e seguintes nos Estados ainda relativamente imunes às ideias do Iluminismo e da Revolução Francesa que o dique do Antigo Regime tentava em vão travar: a diabolização da mulher e do sexo.

Não é, todavia, comparável a situação vivida pelos cativos portugueses no Século XVIII e início do XIX nos Banhos da regência argelina com aquela outra do renegado Simão Gonçalves que, finalmente reconciliado com a sua fé, percorrerá com o infamante sambenito ${ }^{2}$, no ano de 1556, as ruas de Lisboa. Algo terão, no entanto, as duas em comum, a tentativa de prolongar no tempo a imagem negativa do Islão, arma ideológica de justificação sempre necessária de ter à mão para futuros cometimentos da mais variada índole.

Precedendo os seus resgates, cativos em território alauita ou das regências, sobretudo na de Argel, fizeram chegar ao Reino relatos das suas experiências, oferecendo testemunhos vivenciais sobre o cativeiro cristão em terras magrebinas. Mais verídicas e realistas umas do que outras, estas pungentes e curiosas descrições acabaram também por funcionar como suporte ideológico de uma forma do europeu ler o outro lado da fronteira que, embora porosa, não deixava de ser a linha imaginária separandoos do "outro". Muitos participaram assim, conscientemente ou não, na criação de uma lenda negra que ajudaria a manutenção e o desenvolvimento da ideia de missão civilizadora face ao Islão, sustentáculo do desiderato do colonizador e que terá a sua máxima expressão nos Séculos XIX e XX. Por todas estas razões, devemos usar com parcimônia e prudência os relatos de diplomatas, de viajantes ou de cativos com toda a naturalidade almejando o seu resgate.

Resgatados à medida que vários tratados de trégua e paz eram firmados com os seus reinos de origem, os cativos europeus estavam deles dependentes já que aqueles

\footnotetext{
${ }^{2}$ Sambenito: Hábito usado pelos penitentes nos auto de fé da Inquisição.
} 
cujos países apresentavam pendências com as regências eram particularmente visados pelos seus corsários. Era o caso dos portugueses, desde o último resgate do Século XVIII até a paz com Argel de 1813, dos americanos, até a vinda de uma esquadra desta nação ao Mediterrâneo que regulou definitivamente o problema, dos napolitanos e, venezianos, presenças constantes no registo de presas da Regência nas três primeiras décadas do Século XIX, publicado por Albert Devoulx.

À tentativa de fazer passar a imagem do Islão mergulhado na mais completa barbárie, capaz de cometer soezes atropelos a tudo o que estivesse relacionado com a dignidade humana, naturalmente esquecendo o tratamento infligido aos escravos turcos na margem norte do Mediterrâneo e nos Arsenais da Costa Atlântica da Península Ibérica, está normalmente associada à figura do judeu rapace ${ }^{3}$ sempre pronto a lucrar, em nome próprio ou alheio, com o infeliz povo de Cristo a apodrecer nos Banhos magrebinos.

Na obra de Emanuel D’Aranda ${ }^{4}$, essencial para o estudo das condições vividas pelos cativos cristãos em terras do Magrebe e para desmistificar a imagem do Islão que nos é transmitida por muita da literatura europeia do gênero, reaviva-se o conhecimento da forma como os homens de negócio judeus atuavam, de acordo com os detentores de cativos na Regência, para contornar os variados interditos religiosos que os inibiam da posse de cristãos. Por outro lado, a fuga a estes interditos, por vezes obstaculizando o normal desenrolar da atividade econômica nessa zona de fonteira entre a margem norte do Mediterrâneo e o Magrebe, levava ao estabelecimento daquilo a que hoje não hesitaríamos considerar lucrativas joint ventures ${ }^{5}$ entre proeminentes membros das comunidades hebraicas de Tunes e Argel e naturais dessas grandes cidades.

Relações aparentemente inexplicáveis a que interditos de toda a ordem se opunham? E que dizer das cartas recebidas em Portugal, remetidas de Argel, nas quais se reclamava das generosas comissões cobradas por importante homem de negócio da

\footnotetext{
${ }^{3}$ Propenso a roubar, rapinante, roubador. Forma de adjetivação de carácter ideológico usada em muitos textos anti-semitas de meados do Século XX.

${ }^{4}$ Emanuel d'Aranda nasceu em 1614 em Bruges e descendia de uma família espanhola de origem aragonesa. Publicou em Bruxelas (1656) Relation De la captivité, Et liberté Du Sieur Emanuel De Aranda, Mené esclave à Alger en l'an 1640, Mis en liberté l'an 1642. Esta obra teve larga difusão europeia e conheceu uma edição americana (1796), com toda a certeza ligada às tensões vividas no Mediterrâneo entre a Argélia e os Estados Unidos da América no período de 1785 a 1797.

${ }^{5}$ Termo usado para definir uma associação econômica. No caso concreto do espaço magrebino ela era frequente nos Séculos XVIII e XIX entre os crentes das três grandes religiões monoteístas. Não era raro um cativo estar na posse de vários senhores que, quando da sua redenção, naturalmente partilhavam os proveitos auferidos desta transação.
} 
praça de Lisboa pela remessa de fundos destinados ao pagamento de soldadas aos membros das equipagens dos navios de guerra portugueses apresados pelo corso da Regência? Nada que, embora desprezando as mais elementares normas da solidariedade cristã ao mesmo tempo que contribuía para as listas de resgate dos cativos em Argel, o mundo dos negócios não conseguisse superar, unindo e concertando o que aparentemente se apresentava como desavindo.

A mais que conhecida e reconhecida atividade dos judeus sefarditas no intenso tráfico de cativos em todo o Mediterrâneo, através do grande empório que era a cidade de Livorno, onde existia uma importante comunidade judaica de origem portuguesa, é um fato que todo o ocidente europeu não pode ignorar. Portugal foi vítima e beneficiário dessa atividade, já que alguns dos seus navios e muitas das cargas transportadas foram transacionadas na margem norte do Mediterrâneo, através de intermediários judeus. Ao mesmo tempo, membros da comunidade judaica de Argel e Gibraltar intervieram, caucionando empréstimos, nas várias redenções de cativos e pagamentos ao Dey ${ }^{6}$ que antecederam a paz com a regência argelina de 1813.

No primeiro quartel do Século XIX, a Real Fazenda Portuguesa mantinha movimentadas contas-correntes com importantes casas comerciais de Gibraltar, detidas, na sua maioria, por membros da comunidade judaica. Entre elas avultava a Judah Benoliel Arengo \& Ca., ali sediada, credora do Estado Português em alguns milhares de reis, ela própria também contribuinte líquida para as listas de redenção de cativos circulando no Reino na primeira metade dos oitocentos.

Em outubro de 1811, James Scarnichia ${ }^{7}$ esclarece, em carta endereçada a D. Miguel Pereira Forjaz, que Joseph Cohen Bacri tinha ficado por fiador de trinta mil duros exigidos pelo Dey para levar a bom termo as negociações com Portugal. Sabemos também que o "Judeu Cardozo" comercializou a carga transportada pelo bergantim Intrépido, entretanto, apresado pelos corsários da Regência, quando da Bahia rumava ao Reino.

James Scarnichia, na sua justificação das despesas efetuadas com as várias viagens a Argel, faz o balanço do Dever e do Haver dos montantes despendidos e recebidos, fornecendo-nos também importâncias, pequenas é certo mas elucidativas,

\footnotetext{
${ }^{6}$ Título dado aos governantes da Regência de Argel entre 1671 e 1830, data do desembarque das forças francesas em território argelino.

${ }^{7}$ Oficial da Marinha de Guerra portuguesa que conduziu várias missões a Argel com especial relevância para aquela que haveria de redundar no Tratado de Paz com aquela Regência em 14 de Junho de 1813.
} 
adiantadas a cativos portugueses por homens de negócio judeus como auxílio aos seus resgates. É de notar como eram importantes para a subsistência dos cativos de mais baixa condição social, normalmente pescadores e habitantes do litoral algarvio, estes adiantamentos que realmente funcionavam como óbolo e lenitivo para alguém esquecido pela sua pátria.

Não devemos, porém, julgar toda a comunidade judaica da Regência pelos seus membros que realizavam negócios com a Coroa portuguesa ou auxiliavam os seus súditos ali cativos. A realidade é que a comunidade judaica argelina, em 1830, contava com cerca de 25.000 pessoas, a maior parte pobres. A sua miserável condição causou algum espanto e admiração aos invasores franceses.

Tudo isso não impediu que os novos senhores recentemente chegados da margem norte do Mediterrâneo não tirassem proveito da sua situação. No plano oficial, as relações diplomáticas da extinta Regência com os países europeus efetuavam-se por intermédio dos judeus portugueses ali estabelecidos. Os planos franceses de conquista consideravam-nos como possíveis e preciosos auxiliares (STORA, 1991, p. 36). Na realidade, a França colonizaria a Argélia como o judaísmo francês haveria de colonizar o judaísmo argelino, não sem ao mesmo tempo toda a colônia passar por uma vaga de anti-semitismo de grande violência, após a promulgação do Decreto Crémieux, de 24 de outubro de $1870^{8}$. Por detrás do anti-semitismo, perfilava-se, na realidade, o medo do perigo árabe. (STORA, 1991, p. 39).

Por fim, a fragata Pérola da marinha de guerra portuguesa, transportando os últimos cativos nacionais resgatados aos Banhos de Argel, já surta no Tejo, fornecia às autoridades portuárias de Lisboa a sua lista de passageiros. Dela constavam a “[...] Família de Salomão Benoliel, que vem com destino de hir as Caldas" e para o mesmo fim “[...] David Aeriz, Isac Hassam, seu filho, seu irmão e hum criado.” (ARQUIVO HISTÓRICO ULTRAMARINO, 1813). Perante exemplos desses, repetidos ao longo dos Séculos XIX e XX, as relações comerciais com o Magrebe irão continuar a processar-se através das comunidades judaicas portuguesa e norte-africana, oscilando entre o realismo pragmático e o anti-semitismo teológico.

$\mathrm{Na}$ sequência das condições de tratamento que Emanuel D'Aranda constatou serem dadas na sua pátria aos cativos muçulmanos, bem diferentes daquelas outras a que ele próprio tinha sido submetido na sua breve estadia em terras magrebinas,

\footnotetext{
${ }^{8}$ Esse decreto concedeu a nacionalidade aos judeus argelinos que, num ápice, passaram do estatuto de dhimmi (protegidos) que anteriormente possuíam na Regência ao de cidadãos franceses.
} 
especialistas locais oferecem-nos uma outra visão do corso no ocidente mediterrânico, a visão do "outro". É com base no cotejo dessas visões com outras que nos são fornecidas pela documentação portuguesa que se analisará a imagem que a ideologia dominante nos passou do Islão magrebino.

O imaginário ocidental tinha feito do tráfico do homem no Mediterrâneo uma característica dos muçulmanos e da sua forma de ler o mundo que transparecia das missivas e crônicas dos cônsules, padres, viajantes e cativos vivendo o "inferno" da Barbária. Por outro, as agruras dos muçulmanos, cativos condenados às galés ${ }^{9}$ e a trabalhos forçados, eram apenas timidamente afloradas.

São, em algum número, os relatos de viagens por terras magrebinas e de estadias nos Banhos das regências. A esses devemos acrescentar a correspondência e petições reclamando a atenção para os cativos no Magrebe. A passagem do Século XVIII para o XIX é pródiga neste tipo de documentação. Todas estas obras, impressas ou manuscritas, acabam por se revelar, ideologicamente, justificativas de um procedimento que tinha como fim trazer de regresso ao Reino, por intermédio dos Padres Redemptores da Santíssima Trindade, as centenas de portugueses em cativeiro. Seria, porém, errado pensar que, a esse objetivo, outros não estavam associados, nomeadamente os de natureza econômica, política e geoestratégica.

Ao longo de todo o Século XVIII, dirigiram-se os Padres Redemptores oito vezes ao Magrebe. Dessas, duas a Mequinez e seis à regência de Argel, de onde trouxeram consigo 1.587 cativos. Após 1778, ano do último resgate que esses levaram a cabo, a atenção será dirigida a estratos bem definidos da sociedade portuguesa de oitocentos, interessados e capazes de contribuirem para a libertação dos seus compatriotas cativos nos Banhos argelinos. Não se pode, de forma alguma, considerar despiciendo o sustentáculo ideológico que a diabolização da imagem do Islão fornecia à consecução deste objetivo. Também não se pode esquecer que à volta da piedade gerada em relação aos portugueses em cativeiro convergiram interesses de vária ordem, bastando, para isso, consultar a lista de donativos que se tornou pública quando da paz com Argel em 1813. Dela, faziam parte importantes homens de negócio das praças

\footnotetext{
${ }^{9}$ Navio utilizado na guerra e no comércio até ao Século XVIII por todas as potências marítimas mediterrânicas. O facto de ser uma embarcação de baixo bordo tornava-a inapropriada para viagens oceânicas, muito embora tenhamos notícias de comboios de galés no Atlântico e o próprio Luís XIV possuir uma esquadra desse tipo de navios estacionada em Dunkerque, na Costa Atlântica francesa. A tripulação era, na maioria, composta pelos remeiros ou galeotes, além dos artilheiros e soldados. A necessidade de remeiros obrigava as potências cristãs da margem norte do Mediterrâneo a procurá-los avidamente no seio dos criminosos de delito comum e religioso gerados pelas suas máquinas judiciais e, sobretudo, nos escravos turcos e mouros provenientes da actividade corsária.
} 
comerciais de Lisboa e Porto interessados em assegurar o normal desenrolar do tráfego atlântico, necessário à boa continuação das suas transações. É de notar que, para a elite comercial representada nas principais praças do Reino, o tráfico de "graons"10 e gado com o império xarifino e a especulação sobre o comércio frumentário proporcionava avultados lucros que o aumento dos prêmios de seguro em razão da instabilidade e da perda em cargas e navios necessariamente diminuiam.

Acerca das condições de vida dos cativos portugueses tão glosadas nos textos apologéticos do sofrimento cristão da passagem do século e que contribuiram para a elaboração da imagem negativa do Islão na opinião pública portuguesa, reportamo-nos às vividas em Argel. É daí que nos chegam copiosas informações após a perda da fragata da marinha de guerra portuguesa Cisne às mãos dos corsários da Regência.

Nada nos permite duvidar que as informações enviadas por D. Miguel Pereira Forjaz ao chefe de divisão James Scarnichia, relativas aos procedimentos a seguir no resgate dos últimos portugueses cativos na Regência, constituissem uma inovação ou algo de diferente no contexto epocal dos Séculos XVIII e XIX. As prioridades apontadas por esta alta individualidade do poder político em Portugal, eram por si só todo um programa ideológico. Assim, teriam de ser tidas em conta, no momento do seu resgate, três classes de cativos “[...] $1^{\text {a }}$ officiaes de Marinha, de Tropa, Capelães; $2^{\text {a }}$ Marinheiros, Soldados; $3^{a}$ Pescadores, Mulheres, vindo todas as classes em proporção do numero de cada huma, e pela ordem da sua antiguidade no cativeiro". (ARQUIVO HISTÓRICO ULTRAMARINO, 1810a).

Também nada nos permite pôr em causa a existência de cativos turcos no reino português. Nos resgates levados a cabo durante todo o Século XVIII, encontram-se vários que foram trocados por cativos portugueses. No resgate em Argel no ano de 1720, o primeiro do Século XVIII, encontra-se um mouro e um turco; no também efetuado na regência argelina, em 1726, deparam-se-nos seis mouros, seis "colorios" um turco; no resgate de Mequinez, quarenta e nove mouros, valendo cada meio mouro, um cativo português e 360 patacas; no de 1739 em Argel, dez mouros e um turco,

\footnotetext{
${ }^{10}$ Expressão utilizada nos Séculos XVIII e XIX, para designar todo o tipo de cereais. As grandes questões com Marrocos neste período (1774-1820) giram em torno da importação de cereais e gado necessários ao abastecimento da população portuguesa e dos exércitos que operavam no Reino.

${ }^{11}$ Expressão usada na documentação portuguesa dos Séculos XVII e XVIII, nomeadamente nas relações de resgate de cativos dos Padres Redemptores da Santíssima Trindade da Província de Portugal, e que se refere a kulugli (filho da união entre um elemento da oligarquia turca e uma mulher nativa). Notar que a documentação portuguesa da época já referenciava mouros, turcos e colorios com todas as diferenças sociológicas daí resultantes.
} 
referidos como de "galé". Estes números permitem-nos afirmar que a existência de muçulmanos cativos e escravos em Portugal foi uma realidade que dificilmente pode ser ignorada, ainda que pouco ou nada estudada.

Em maio de 1810, no decurso de novas negociações com a Regência, voltamos a encontrar listas das quais fazem parte cinquenta e dois turcos " [...] existentes na Cadeia da Gallé do Real Arsenal da Marinha”. (ARQUIVO HISTÓRICO ULTRAMARINO, 1810b). Pouco sabemos acerca das reais condições de vida dos escravos turcos na cadeia da marinha em Lisboa, ou se outros havia em idêntica situação espalhados pelo país. Arriscamo-nos, todavia, a afirmar que elas não seriam de forma alguma idênticas às vividas pelos cristãos nos Banhos das regências berberescas e do império xarifino que nos são descritas para o Século XVII por Emanuel D’Aranda, para o Século XVIII por Venture de Paradis e relativamente ao Século XIX por vária documentação jazendo nos arquivos portugueses.

Fato importante, um pouco ao arrepio da imagem negativa do Islão magrebino, é o passado no resgate de 1726 que devolveu ao Reino duzentos e quatorze cativos retidos em Argel. Na introdução que precede a lista dos resgatados é feita referência a uma imagem de Cristo transportando a cruz, provavelmente a do Senhor dos Passos, que fazia parte da carga da charrua Nossa Senhora da Penha de França, saída do Porto com destino à Bahia. Essa imagem foi alvo de tratos de polé por parte dos mouros que dela

[...] zombarão e escarnecerão no anno de 1723 [e] a cuspirão, derão bofetadas, e arrastarão pela tolda do Navio, rasgando-lhe a Tunica, que entre si mesmo dividirão, a levarão a Argel, aonde no Baptistão, lugar dos Leilões, foy publicamente vendida, e rematada, competindo nos lanços huns Judeos que a queriam comprar. (RELAÇÃO, 1726).

Competiram na arrematação os judeus com um cristão, Silvestre Xavier, natural da Ilha do Faial, cativo do governador de Argel. Este português acabará por ver a imagem em disputa ser adquirida pelo seu senhor que lha ofertará. Depois, será depositada no Hospital da Ordem da Santíssima Trindade na capital da Regência e deduzido o seu valor no montante do resgate do cativo português. Caso exemplar, não isolado, de altruísmo, bondade e respeito religioso de um senhor pelo seu cativo, face à atitude mais pragmática dos Padres Redemptores que não se eximiram a aceitar a sua dedução no valor do resgate, tomando posse dela num lugar para o qual não existia equivalente no reino português em relação aos muçulmanos aí escravos e cativos. 
São, porém, os relatos que chegaram da fragata Cisne que nos dão uma noção mais exacta de como eram as estadias dos portugueses, pelo menos daqueles de condição social mais elevada, nos Banhos do Magrebe. No essencial, elas não diferem muito de outras vividas em séculos anteriores, sendo apenas agudizadas quando os conflitos entre a Cristandade e o Islão se agravavam ou quando o poder em Argel pretendia pressionar qualquer potência cristã.

Não existem informações acerca de todos os cativos, já que aqueles que D. Miguel Pereira Forjaz incluía na segunda e terceira classes das instruções remetidas a James Scarnichia, marinheiros, soldados, pescadores e mulheres, não possuíam voz. As suas petições, quando nos chegam, são geralmente redigidas por terceiros e segundo textos pré-definidos.

As pressões sofridas pelos cativos de maior relevo social também foram relevantes e, embora não sejam comparáveis às enfrentadas por outros, elas eram um meio de tentar apressar futuros acordos diplomáticos, tributos em dinheiro e fornecimento de matérias-primas de alto valor estratégico à regência argelina.

Em maio de 1802, o oficial português Paulo Freire de Andrade informava para o Reino estarem todos os cativos a trabalhar nas obras públicas com grilhetas nos pés, carecendo de tratamento e cuidados médicos. Todavia, no mesmo documento, aduzia terem sido enviados alguns oficiais de patente para casa de cônsules estrangeiros. Na mesma data, Joaquim José de Castro Guedes, também graduado da marinha de guerra, escrevia a seu pai em Lisboa dando-lhe conta da sua situação, da estadia em casa do cônsul da Suécia e acrescentava que quem efetivamente trabalhava era a gente da equipagem, sendo a população da cidade asperamente castigada quando os fazia sofrer maus tratamentos. Alguma parcimônia na descrição das condições de vida na regência argelina resulta, quanto a nós, do receio que possíveis indícios de tratamento mais humano, contrariando a ideia do "bárbaro infiel" vigente no Reino, viessem a redundar num efeito dilatório na efetuação dos resgates. Curiosa imagem de um Islão do qual persistiam, no imaginário português, vastas impressões negativas e que depois, na prática, se revelava acolhedor e inclusivo.

Em dezembro de 1802, Paulo Freire de Andrade voltava a escrever ao visconde de Anadia e na carta que lhe dirigia manifestava os seus cuidados por eventuais adesões ao Islão. Tinha em conta a miséria vivida no seio das guarnições dos navios portugueses, abandonadas pelas autoridades de Lisboa, sofrendo contínuos atrasos no 
pagamento dos seus soldos, contando alguns dos seus membros dezenas de anos de cativeiro.

Haveriam de se revelar excessivas as preocupações do oficial português já que as conversões, que de fato existiram, não foram abundantes. Na realidade, o Islão, e mais particularmente a regência de Argel, já não suscitava, nas tripulações cristãs ali cativas, o interesse que tinha exercido em séculos anteriores, apesar do longo braço da Inquisição. Os ganhos do corso tinham sofrido uma sensível diminuição. E no império xarifino, os anos dourados do Século XVI eram apenas uma saudosa recordação, como também o era o reinado de Mawlay Ismail. No Magrebe, já não existia o clima de licenciosidade e liberdade que tanta atração tinha exercido em homens como Simão Gonçalves e em tantos outros que haviam trocado a cruz pelo crescente. Aos cativos portugueses interessava mais regressar ao Reino, embora a miséria que os aguardava no Lazareto da Trafaria pouca diferença fazia daquela vivida em Argel e as dificuldades na reinserção fossem a realidade que os esperava. Apenas a fome e o desinteresse do poder político em Lisboa poderiam exercer sobre eles, como aliás em alguns casos veio a acontecer, alguma pressão.

Em 1830 a França consumou a intervenção na regência argelina. A conjuntura internacional e as novas implicações geoestratégicas que esta induzia, levaram as potências europeias a interessarem-se cada vez mais pelo espaço magrebino.

A complementaridade da política externa portuguesa em relação ao Magrebe, iniciada em 1774 com o Tratado com Marrocos e atingida em 1813 com o acordo com a regência de Argel, perdia em parte muita da sua razão de ser face à nova ordem internacional que se desenhava nas chancelarias europeias e nos campos de batalha da Europa e do Norte de África. Portugal viu acentuar-se a sua condição periférica e a dependência dos complicados acertos estratégicos que tinham lugar no Velho Continente.

O exotismo romântico e a pretensa superioridade civilizacional, sempre associada a acordos com as potências dominantes, passam então a ser maioritários na representação da realidade magrebina na sociedade portuguesa de meados de oitocentos. Esses tinham-se sobreposto aos dois outros vetores que caracterizavam, no plano ideológico, a sociedade europeia nas suas relações com outras realidades culturais: o imperialismo e a especialização. A inexequibilidade de uma política imperialista em função da exiguidade de meios e recursos de um pequeno país. A inexistência em Portugal de uma Escola de línguas orientais, à semelhança daquela que foi estabelecida 
em Paris pela Convenção, no ano de 1795, levou a que não tivesse sido dado o passo em direção à associação com as ciências humanas e que redundaria no aparecimento de especialistas na área do Islão e, mais particularmente, naquela relacionada com a sua vertente magrebina.

O Islão sempre ocupou lugar de relevo nas páginas da imprensa portuguesa contemporânea. Nessas, cruzam-se as mais variadas referências, desde as questões relativas ao Império Otomano até às magrebinas, com especial relevo para as relacionadas com o território alauita nos primeiros anos do Século XX.

O grande acontecimento que marca o final dos oitocentos é a conferência de Madrid em 1880. O sucesso que a diplomacia portuguesa ali alcançou não se repetirá em Algeciras, no ano de 1906. A imprensa de Lisboa deu significativo relevo a esta reunião internacional, veiculando assim uma forma de ler o Islão magrebino que irá marcar os primeiros anos do Século XX.

Contra o que era usual em períodos anteriores, os jornais relegaram para segundo plano os habituais despachos, geralmente sob o título "Questão de Marrocos", para, com periodicidade quase diária, publicarem interessantes artigos entre os quais se podem encontrar vários assinados por diplomatas portugueses que prestaram serviço no Magrebe. Será preciso esperar mais alguns anos para reencontrar matéria tão esclarecedora que nos permita aquilatar da importância da imagem desfrutada pelo Islão na sociedade portuguesa da primeira metade do século.

A década inicial de novecentos revela-nos um incipiente comércio de exportação em direção ao Norte de África, contrabalançado por importações de alguma forma relevantes. De Bona e Orão chegavam-nos fosfatos, esparto e, mais esporadicamente, trigo; de Sfax, fostatos; de Marrocos, grande variedade de cereais, cujo transporte era geralmente efetuado em navios de bandeira portuguesa.

Em Lisboa, agentes de navegação representavam armadores de várias nacionalidades interessados no jogo de influências do espaço magrebino e com carreiras marítimas em direção aos portos da costa oriental de África. A casa Henry Burnay \& Ca. agenciava os navios da Compañia Trasatlântica e da Société Navale de l'Ouest; Hahnefeld \& Gelweller representava o Servizio-Italo-Spagnuolo; Ernest George, Sucessores, oferecia os serviços da Deutsche Ost-Afrika-Linie, Stoomvaart Matschappy Nederland - Roterdamsche Lloyd e Lloyd Norte Alemão.

Os negócios de importação e exportação relacionados com o Norte de África continuavam a processar-se através de casas comerciais, maioritariamente detidas por 
elementos da comunidade judaica, J.A. Levy \& Ca., A.D. Benchimol e J.Toledano, que se deslocavam com regularidade entre Tânger e Lisboa.

No início de 1906, a imprensa publicada em Lisboa acompanhou evolução dos acontecimentos na conferência de Algeciras. Antes do início desta importante reunião, surgiu nas páginas de $O$ Século, sob o título "Portugal e Marrocos", um significativo artigo acerca da complicada situação política portuguesa. Nele, recorrendo à ambivalente imagem do Islão magrebino, faz-se uso do neologismo "marroquinisar" para adjetivar negativamente o ambiente político vivido em Portugal. Criticava-se a notória tendência para nos "marroquinisarmos", para sermos "marroquinos" sob o ponto de vista administrativo, "marroquinos" sob o ponto de vista financeiro, e, ainda sob diversos outros pontos de vista. Continuava o articulista dizendo que a nossa situação ainda era pior do que a dos "marroquinos", pois que o que eles, por atraso de civilização, nunca tinham possuído, estávamos nós, por inércia e desleixo, deixando estragar. Por fim, concluía:

[...] o que quer dizer que, sendo pequena a diferença entre uns e outros, materialmente encarada, - o que já depõe muito pouco em nosso favor, moralmente, - o que depõe muito menos, - ainda é menor. Por outras palavras: em quanto elles apenas se teem conservado parados nós retrogradamos! É triste mas é assim mesmo. (BIBLIOTECA NACIONAL DE PORTUGAL, 1906d).

Que dizer desta esclarecedora prosa, senão que ela espelhava a visão do Islão magrebino ainda não totalmente sob o domínio francês e que de forma anacrônica se transmitiu à ação da delegação portuguesa em Algeciras.

Em 19 de janeiro de 1906, o Jornal do Comércio, juntamente com outros periódicos de referência, iniciou a cobertura da conferência de Algeciras. Esclarecia a razão da sua convocação; descrevia o Palácio da Conferência, a primeira sessão; enumerava os delegados das nações; e dava conta da eleição do seu presidente. Informava também a composição da delegação portuguesa: conde de Tovar, ministro plenipotenciário em Madrid, e o conde de Martens Ferrão, enviado extraordinário em Tânger.

Em 20 de janeiro de 1906, o mesmo periódico publicava parte do discurso de abertura da conferência pronunciado pelo duque de Almodovar no qual esse, tendo como objetivo o reinado da ordem, da paz e da prosperidade em Marocos, afirmava: "As potencias concordam igualmente em reconhecer que tão precioso fim só poderia 
alcançar-se mediante a introdução de reformas no Império, baseadas no triplice principio da soberania do Sultão, da integridade dos seus estados e da igualdade isto é, a porta aberta." (BIBLIOTECA NACIONAL DE PORTUGAL, 1906b - Grifos do autor). Esse discurso, todo um programa de domínio civilizacional, não é todavia bem compreendido em Lisboa, que vive ainda das glórias passadas.

A imprensa critica a apagada e vil tristeza em que vive a delegação portuguesa, que não sabia tirar o devido proveito do prestígio diplomático de que ainda desfrutava em Marrocos o barão de Colaço. Lamentava igualmente não serem usados os ensinamentos do conde de Casal-Ribeiro, de quem, com saudade, se lamentava a ausência, o mesmo que alcançara em Madrid o estatuto de nação mais favorecida para Portugal.

Em 4 de abril de 1906, o Jornal do Comércio dava à estampa um artigo intitulado "Figura de Portugal na conferência". Nele, se fazia o balanço da participação portuguesa e se reclamava do fato de o país não participar do "banquete" em Marrocos. O colonialismo, ou as suas novas formas, preparava-se para cair sobre o império dos xarifes. A imagem de aparente debilidade civilizacional do Islão magrebino vigente em Portugal da qual, segundo os entendidos em Lisboa, não se conseguia tirar o devido proveito, agudizava as frustrações nacionais e as suas inconsistências políticas. Escrevia o jornal de Lisboa:

E Portugal, dir-me-ha algum curioso - não poderei dizer algum patriota - o que fez? Fez o que fez sempre que o apoio de cima lhe falta, ou que o impulso de dentro lhe fenece. Não fez nada. Disse que sim quando e depois da Inglaterra ter dito que sim, pela mesma forma e pelas mesmas razões que diria que não se antes tivesse ouvido esta negativa.

Ninguém sábe, afóra isto, o que ali fizeram os delegados portugueses por, cujo immenso talento e maior patriotismo temos alias o maximo acatamento. Mas esses mesmos talentos e patriotismo clamam por acção, exigem exercício, devem manifestar-se como a luz do sol, para que todos o vejam, reconheçam, apreciem e exaltem.

Vimos aqui por elles clamando ha mais de um mez. Vox clamantis in desert!

Soubemos da nossa chancellaria, que outrora fez tremer a Europa, que algo se preparava, discretamente, para não ferir melindres [...]. E agora cae um ministério, sobe um outro, fecha-se a Conferencia de Algeciras, e ainda não é lícito saber do que fizeram os delegados portugueses?![...]

Oh cumulo do cumulos da ingenuidade [...]

Descobrimos, conquistámos, arroteámos a terra, pescámos no mar, negociámos a paz, e por fim [...] acompanhámos os outros na partilha do que foi nosso e ainda podia voltar a ser nosso! 
Que futuro d'escravos nos reservará esta subserviencia baixa e esta imprevidencia tonta?! (BIBLIOTECA NACIONAL DE PORTUGAL, 1906c).

Os sempre incontornáveis, no que diz respeito aos assuntos magrebinos, membros da família Colaço voltam, com a autoridade que todos lhes reconheciam, a fazer ouvir a sua voz. Em janeiro de 1904, nas páginas de $O$ Século, o seu colaborador artístico, Jorge Colaço, discorria sobre a importância dos mares de Marrocos para a subsistência das pescas portuguesas e mais concretamente dos pescadores algarvios. Afirmava, também, que se deveria dar especial importância às questões marroquinas e ao interesse que essas suscitavam na comunidade internacional.

Duas décadas depois será grande o número de indivíduos, a maioria fugindo ao serviço militar, que, via marítima, sem documentos, sairão do continente embarcando em navios de Olhão. ${ }^{12}$ Essa gente rumará a Gibraltar, Casablanca, Tânger (OUTEIRO, 1926) e irá engrossar a comunidade portuguesa de Marrocos da qual nos falará mais tarde Urbano Rodrigues. Emigrantes forçados, arredados das grandes discussões teóricas do seu tempo, provarão na prática o carácter inclusivo do Islão e a sua universalidade.

Vai ser, porém, a colaboração de um outro membro da dinastia dos Colaço que irá encerrar este período dos primeiros anos do Século XX, antecedendo a implantação da República. Em março de 1906, José Daniel Colaço, $1^{\circ}$ barão de Colaço e Macnamara, escreveu uma carta que o Diário de Notícias publicou com o devido relevo e que também teve grande audiência na restante imprensa de Lisboa. Congratulando-se com o fim da indiferença com que durante anos se tinha ouvido falar de Marrocos nos países que ali não possuíam territórios, louvava os resultados alcançados em Algeciras em que:

[...] as potências civilizadas acordando do lethargo em que se achavam ácerca de Marrocos, concordam em que não deve ficar inculto e exposto a ser somente utilizado por uma ou duas nacionalidades estrangeiras aquelle vasto dominio tão abandonado como proximo do foco luminoso da civilização denominado Europa, assemelhando-se pela grosseira capa obscura que envolve as promettedoras entranhas, como que a um grosso diamante em bruto, que na epoca actual contraria a privilégios, deve ser lapidado em beneficio de todos os interessados. (BIBLIOTECA NACIONAL DE PORTUGAL, 1906a).

\footnotetext{
${ }^{12}$ Navios oriundos de Olhão, vila costeira do Algarve, província do sul do território português, que se dedicava a uma intensa atividade piscatória. A Costa Sul de Portugal, bem como a principal atividade das suas populações, a pesca, sempre foi um alvo privilegiado dos piratas barbarescos e dos seus êmulos cristãos.
} 
Portugal inseria-se, assim, na ideologia dominante no espaço europeu em relação ao Norte de África. Apenas uma preocupação atingia os especialistas nacionais: o diamante em bruto, Marrocos, deveria ser lapidado em benefício de todos os interessados.

Continuava o barão de Colaço e Macnamara pugnando pela manutenção dos direitos portugueses em matéria de pescas, por ele já alcançados em 1860, quando desempenhava funções diplomáticas em Marrocos, consignados no artigo 17 da convenção de Madrid. Terminava avisando para as naturais resistências ao progresso que, com toda a certeza, seriam encontradas pelas potências europeias signatárias de Algeciras, as quais não deveriam ser estranhas num “[...] paiz de tradicional e arreigado fanatismo alkorânico.” (BIBLIOTECA NACIONAL DE PORTUGAL, 1906a).

Em 1935 e 1942, são publicadas, em Lisboa, duas obras do jornalista e escritor Urbano Rodrigues. A primeira, que aborda uma estadia em Marrocos e pode ser considerada no subgênero literário da literatura de viagens, deve contudo ser aqui analisada tendo em conta a imagem do Islão que transmite. Ela prolonga, quanto a nós, a do início do século, que nos mostra um Islão exótico visto pelos olhos de um observador saudoso de glórias passadas impossíveis de reviver tendo em conta o seu anacronismo à luz da conjuntura europeia da época.

Declarando, logo no início, que uma excursão ao Norte de África não era para um português um passeio como qualquer outro, o autor afirmava que "[...] visitar Marrocos é ir a um dos nossos lugares santos, ir afervorar o amor pátrio e retemperar a alma" (RODRIGUES, 1935, p. 9) e associava à tentativa de recuperação de um lugar relevante para Portugal no conjunto das questões magrebinas o reconhecimento do papel da França neste processo, “[...] são os próprios franceses, os protectores de Marrocos, que nos encorajam, mostrando conhecer o nosso presente melhor do que conheciam o nosso passado, mostrando-se a par do nosso esfôrço para nos bastarmos e nos erguermos, dizendo-se admiradores do nosso renascimento." (RODRIGUES, 1935, p.10-11).

Iniciou-se a viagem do escritor português por Tânger, "[...] sem dúvida, a grande porta de Marrocos" (RODRIGUES, 1935, p. 17), e ali afirma viver Mawlay Abd El Aziz:

[...] sultão destronado, abandonado pelos seus súbditos porque abriu as portas aos franceses. Hoje todos os mouros o respeitam. Consideram-no um santo, beijam-lhe com devoção a gelaba alvísssima quando desce á sexta-feira, a pé, 
muito aprumado, até ao socco chico para rezar na velha mesquita. Quási sem fortuna, o "filho da escrava querida" de Muley Hassan vive de uma larga pensão que o Govêrno da República Francesa lhe atribui. (RODRIGUES, 1935, p. 18-19).

O tardio exotismo romântico que impregna toda essa obra de larga repercussão pública - não nos esqueçamos que ela é, em grande parte, uma compilação de artigos publicados no Diário de Notícias de Lisboa - está bem patente na descrição da medina de Tânger. Todavia, a espaços, encontramos também, porque isso subsiste naturalmente na memória histórica portuguesa, a atribuição de créditos à imagem civilizacional que o Islão magrebino deixou no ocidente da Ibéria:

\begin{abstract}
A semelhança das culturas faz-nos pensar se fomos nós que ensinámos os mouros, quando ali viemos, ou se foram êles que nos ensinaram quando estiveram na Península. É um problema delicado a resolver. Tudo que ha velho e lendário no Sul de Portugal, principalmente, diz-se que é dos mouros, se não se sabe de quando é; em Marrocos, tudo quanto é antigo, quanto representa grandeza, audácia, seja fortaleza desmoronada ou história de feitos valorosos, é dos portugueses! São dois povos ligados, desde séculos, por boas e más recordações, mas que mútuamente se respeitam e admiram. (RODRIGUES, 1935, p. 47).
\end{abstract}

Mas, da invocação permanente das glórias passadas e do apelo constante a uma maior participação portuguesa nas grandes decisões respeitantes ao Norte de África, o que restava? Quanto a nós, apenas milhares de operários portugueses trabalhando nas obras de Casablanca, Rabat, Mequinez e entre os quais se encontrariam muitos daqueles que, na década de vinte, teriam embarcado clandestinamente ao largo de Olhão. Restava Joaquim Costa, o homem de Mequinez, saído de Tomar, com uma colher e fio de prumo, então já multimilionário, tudo alcançado no âmbito de um processo de colonização que Urbano Rodrigues haveria mais tarde, na sua obra de 1942, de considerar exemplar.

Todavia, serão outras informações que realmente nos interessam. Mais uma vez enaltecendo o processo civilizacional francês que já atingia os territórios do Sul, onde, entretanto, já começavam a chegar "[...] os feiticeiros do martelo e da colher" (RODRIGUES, 1935, p. 85-86), deparamos com a admiração do general Hurot. Foi lá bem a Sul que o militar francês, não conseguindo dissimular o seu espanto, encontrou um português vivendo perfeitamente integrado nas tribos que se lhe renderam. Somos mais uma vez postos perante as capacidades de atração e acolhimento do Islão 
magrebino às quais se juntavam as naturais características dos portugueses no relacionamento com outras culturas.

Nesta obra de 1935, prodigaliza-se já todo um conjunto de elogios à presença francesa em Marrocos que atingirá o seu expoente, em 1942, quando da publicação do outro livro marroquino de Urbano Rodrigues. Na primeira obra, encontramos a afirmação de terem sido D. Sebastião, rei de Portugal, e Lyautey, marechal de França, os maiores cavaleiros que pisaram terras marroquinas, para além de ser considerado o oficial francês como o homem necessário à construção do novo Marrocos, conseguindo o trabalho notável de estabelecer a paz, a ordem e o progresso neste país.

A imagem transmitida nestas duas obras sobre Marrocos, credoras de toda a ideologia que sustenta os pressupostos fundamentais da colonização francesa no Norte de África, não nos pode fazer esquecer o essencial; pedia-se ao povo do Magrebe que se sacrificasse em defesa do sistema francês e dos seus valores ao mesmo tempo que se lhe negava o direito à cidadania.

O livro, editado em 1942 e de autoria de Urbano Rodrigues, foi prefaciado pelo general Nogués. O militar francês reconhecia no seu autor, que tinha seguido passo a passo a obra de Salazar, as condições privilegiadas para compreender o sentido da ressurreição francesa de que o marechal Pétain era, ao mesmo tempo, o animador e o símbolo, o que cauciona e legitima todo um discurso desenvolvido ao longo de mais de cem páginas. A grande obra do general Nogués, título do capítulo V deste livro, que se reconhece e elogia, como também se reconhece e elogia a capacidade de convívio do português com a população muçulmana, indissociável da saudade do império, não é bastante para fazer esquecer o papel secundário reservado ao Islão magrebino como ator do seu futuro.

À inquestionável capacidade de relacionamento dos portugueses, devia-se o fato, segundo Urbano Rodrigues, de os franceses, depois de estabelecido o Protectorado, terem feito deles, os seus melhores colaboradores. Lyautey, de largo e generoso espírito, acabaria por caucionar esse procedimento ao não ter procurado apagar os vestígios do seu domínio, mas sim, ter ordenado a sua digna conservação por certo tendo em conta o respeito pelo heróico passado lusitano. 
Em 1942, Norberto Lopes publica, em Lisboa, uma obra resultante de viagem a Argel ao encontro de Manuel Teixeira Gomes ${ }^{13}$ com estudo de João de Barros. O livro excede em muito a ideia inicial do autor de "[...] reünir numa plaquette as entrevistas que fêz com Teixeira Gomes em Bougie.” (LOPES, 1942, p. 24). Para nós, assume especial relevo o capítulo IV "No exílio". Nesse, respira-se a cada passo a imagem de respeito e admiração pelo Islão que Teixeira Gomes tenta transmitir aos seus amigos mais íntimos e através desses aos seus contemporâneos. Não resistimos a transcrever parte da carta do ex-presidente da República Portuguesa ao pintor Columbano citada por Norberto Lopes:

\begin{abstract}
Nascido e criado no Algarve, onde então as amas contavam aos meninos lendas de moiras encantadas, e onde ainda hoje se respira algo de muçulmano na atmosfera, na linguagem, e nos usos e nos costumes, talvez atavicamente preparado também por antecedentes de geração, para apreciar os conhecimentos da sensualidade e da poesia árabe, foi sempre aspiração minha visitar as terras da moirama. Isso o consegui, relativamente novo, nos muitos anos a fio, durante os quais, por cinco ou seis meses cada ano, percorri as costas do Mediterrâneo. A afinidade congénita mais se avigorou nas viagens, e hoje, velho como sou, se tivesse de mudar de nacionalidade, era entre sarracenos que de preferência a buscaria. E tudo me incita e convida a tomar tal resolução! $\mathrm{Na}$ minha idade, com o rosto engelhado, a barba encanecida, os movimentos entorpecidos, o trajo europeu, que desenha rigorosamente o corpo por um figurino apolíneo, é soberanamente ridículo. Não sucede outro tanto com a túnica, o albornoz e o turbante, que até imprimem á figura do ancião um aspecto de nobre gravidade, próprio para inspirar respeito e venereção. (LOPES, 1942, p. 216-219).
\end{abstract}

Aos sentimentos manifestados a Columbano, juntou Manuel Teixeira Gomes o saber de experiência feito dado pela permanência, facilitada pelos seus conhecimentos de árabe, vasta cultura e abertura ao outro, junto de uma tribo de nômadas percorrendo o território tunisino, o que lhe proporcionou horas de conversa com homens que guardavam na sua memória toda a brilhante tradição do Islão magrebino.

Nas mais de oito décadas que mediaram entre a data do seu nascimento, em Portimão, em 1860, e a sua morte, em 1941, na então cidade de Bougie, muitos acontecimentos tiveram lugar por todo o Magrebe. O olhar europeu sobre este conjunto político, geográfico e religioso tinha sofrido substanciais alterações que não possuiam

\footnotetext{
${ }^{13}$ Manuel Teixeira Gomes (1860-1941) nasceu em Portimão. Ministro de Portugal em Londres nomeado pelo Governo Provisório em 23 de março de 1911. Ministro em Madrid nomeado em 11 de fevereiro de 1919, voltando a Londres em 24 de abril de 1919. Fez parte da delegação portuguesa à Conferência de Paz e à Sociedade das Nações. Em 6 de agosto de 1923 foi eleito Presidente da República e renunciou ao cargo em 11 de dezembro de 1925. Desiludido com as dificuldades e obstáculos encontrados nos tempos conturbados do seu mandato, partiu para o estrangeiro não mais voltando a Portugal. Fixou-se na Argélia onde acabaria por falecer na atual Béjaia. É autor de importante obra política e literária.
} 
equivalente no espaço português, tanto ao nível das suas elites como da restante opinião pública.

O reconhecimento da especificidade muito própria do valor civilizacional que o Islão representava e, mais concretamente, aquele que se vivenciava no Magrebe, transmitido por Manuel Teixeira Gomes a Norberto Lopes, marca a transição para o aparecimento de um conjunto de estudiosos em Portugal que irão tentar cultivar a imagem positiva que o Islão atualmente desfruta na sociedade portuguesa.

Passados os tempos do fim do Império, regularizadas as pendências com as entidades políticas magrebinas, libertos os últimos cativos portugueses nas regências do Magrebe e no império xarifino, encetado o regresso de Portugal à sua verdadeira dimensão estratégica, restava apenas um caminho: o do reconhecimento da universalidade do Islão.

\begin{abstract}
This article, based on documentation from eighteenth to twentieth centuries, makes a brief incursion to the image of Maghreb's Islam known in Portugal. Captivity narratives of Portuguese citizens in Algiers Regence versus ideological productions printed in Portugal justified the misunderstanding of a reality that was still devaluated although it was important to the strategic health of the Portuguese State. To contemporary status quo of a barbaric Maghreb, it was opposed the image of an inclusive Islam more tolerant than other political realities in the north edge of the Mediterranean Sea.
\end{abstract}

Keywords: Captives; Corsairs; Islam; Maghreb; Jews. 


\section{Referências}

\section{Fontes Manuscritas}

ARQUIVO HISTÓRICO ULTRAMARINO DE LISBOA. Norte de África. Documentação Avulsa. Cópia da Carta de Martinho de Melo e Castro para o Governador da Província da Duquela, datada do Palácio de Queluz, Cx 389, a 24 de novembro de 1794.

ARQUIVO HISTÓRICO ULTRAMARINO DE LISBOA. Norte de África. Documentação Avulsa. Reflexões sobre a necessidade da paz com Marrocos, Cx. 389, [179-].

ARQUIVO HISTÓRICO ULTRAMARINO DE LISBOA. Norte de África. Documentação Avulsa. Reflexões sobre as vantajens de um Tratado de Paz com a Regência de Argel, Cx. 393, [1790?].

ARQUIVO HISTÓRICO ULTRAMARINO DE LISBOA. Norte de África. Documentação Avulsa. Instruções de D. Miguel Pereira Forjaz ao chefe de divisão James Scarnichia, Cx. 413, datadas de Lisboa, a 25 de agosto de 1810a.

ARQUIVO HISTÓRICO ULTRAMARINO DE LISBOA. Norte de África. Documentação Avulsa. Lista de Passageiros que vem a bordo da Fragata Perola, Cx. 407, surta no Tejo 9 de julho de 1813.

ARQUIVO HISTÓRICO ULTRAMARINO. Norte de África. Documentação Avulsa. Carta do príncipe D. João ao pretendido rei de Marrocos, datada do Palácio de Queluz, Cx. 421, a 16 de abril de 1796.

ARQUIVO HISTÓRICO ULTRAMARINO. Norte de África. Documentação Avulsa. Carta de Frei Manuel Rebelo da Silva para D. Miguel Pereira Forjaz, datada de Lisboa, do Convento de Nossa Senhora de Jesus, Cx. 426, a 9 de março de 1814.

ARQUIVO HISTÓRICO ULTRAMARINO. Norte de África. Documentação Avulsa. Lista dos turcos na Cadeia da Gallé do Real Arsenal da Marinha, Cx. 429, em 15 de maio de 1810 b.

\section{Fontes Impressas}

BIBLIOTECA NACIONAL DE PORTUGAL. Periódicos. Diário de Notícias, n.14466, Lisboa, 6 de Março de 1906a.

BIBLIOTECA NACIONAL DE PORTUGAL. Periódicos. Jornal do Comércio, n. 15606, Lisboa, 20 de Janeiro de 1906b.

BIBLIOTECA NACIONAL DE PORTUGAL. Periódicos. Jornal do Comércio, n. 15665, Lisboa, 4 de Abril de 1906c. 
BIBLIOTECA NACIONAL DE PORTUGAL. Periódicos. O Século, n. 8631, Lisboa, 8 de Janeiro de 1906d.

BRISSON, Pierre Raymond de. História do naufrágio e cativeiro de Mr. De Brisson com a descripção dos desertos d'Africa, desde o Senegal, até Marrocos, escrita, e publicada por ele mesmo em 1789. Lisboa, Off. de Simão Thaddeo Ferreira, 1800. 265p.

D'ARANDA, Emanuel. Les captifs d'Alger. Texte établi par Latifa Z'rari. Paris: Éditions Jean- Paul Rocher, 1997. 279p.

DEVOULX, Albert. Le Registre des Prises Maritimes. Traduction D'un Document Authentique et Inédit Concernant Le Partage des Captures Amenées par Les Corsaires Algériens par Albert Devoulx. Alger: Typographie A. Jourdan, 1872. 111p.

LOPES, Norberto. O Exilado de Bougie. Lisboa: Parceria A. M. Pereira, 1942. 302p.

LEMPRIÈRE, Guilherme. Viagens de Gibraltar a Tangere, Salé, Mogador, Sta. Cruz, e Tarudante, e d'ahi pelo Monte Atlas e Marrocos. Lisboa, Off. Simão Thaddeo Ferreira, Lisboa, 1794. 461p.

NOVA Relação de hum Grande Terremoto que no dia 9 do mez de Dezembro do anno de 1752. Succedeo na cidade de Tunes, Capital do Reyno de Argel: Calamidades, que experimentarão aquelles Barbaros na prezente secca; noticia de algumas expiações ridículas, que tem feito para applacar o seu falso Profeta, copiado de huma Carta que escreveo hum Marinheiro cativo naquella Cidade, natural da Ericeira, Lisboa, Na Officina Alvarense, 1753. 4p.

NOVA relação e verdadeira noticia exposta ao publico do grande cazo, que succedeo a hum Cavaleiro Italiano, e a outro Valerozo Espanhol, chamado; Pedro Pisarro na cidade de Argel e dos grandes martírios, que este padeceo pela Fé de Christo na mesma Cidade cuja noticia se remeteo de Gibraltar a esta Corte, Lisboa, Na Officina de Jozé Filippe, 1763. $14 \mathrm{p}$.

PARADIS, Venture de. Tunis et Alger au XVIIIe siècle. Mémoires et observations rassemblés et présentés par Joseph Cuoq. Paris: Sindbad, 1983. 292 p.

RELAÇÃO dos crueis castigos que derão na cidade de Argel a dezasseis captivos christãos. Que por querem a sua liberdade, por se verem em rigoroso captiveiro, forão apanhados na sua fugida, Lisboa, s.n., 1758. 8p.

RELAÇÃO do resgate que por ordem delrey nosso senhor D. João V, rey de Portugal, se fez na cidade de Argel pelos padres Redemptores os prégadores geraes Fr. Joseph de Paiva, e Fr. Simão de Brito da Ordem da Santissima Trindade da Redempção de Cativos da Provincia de Portugal. Lisboa Occidental: Na Officina da Música, 1726. 14p. Disponível em: <http://purl.pt/14757/1/index.html>. Acesso em: 26 ago. 2010.

RODRIGUES, Urbano. A França em Marrocos. Lisboa: Parceria A. M. Pereira, 1942. $138 \mathrm{p}$. 
RODRIGUES, Urbano. Passeio a Marrocos. Lisboa: Empresa Nacional de Publicidade, 1935. 139p.

\section{Livros e artigos}

BELHAMISSI, Moulay. Histoire de La Marine Algerienne (1516-1830). Alger: ENAL, 1983. 187p.

BENNASSAR, Bartolomé; BENNASSAR, Lucile. Les chrétiens d'Allah: L'histoire extraordinaire des renègats: XVIe et XVIIe siècles. Paris: Perin, 2006. 595p.

BENJELlOUN, Therese. Visages de la diplomatie marocaine depuis 1844. Casablanca: Éditions EDDIF, 1991. 256p.

BERRAMDANE, Abdelkhaleq. Le Maroc et L'Occident. Paris: Khartala, 1987. 447p.

CAMAU, Michel. LaTunisie. Paris: PUF, 1989. 125p.

FRÉMEAUX, Jacques. La France et l'Islam depuis 1789. Paris: PUF, 1991. 291p.

JULIEN, Charles-André. Histoire de L'Afrique du Nord: Des origines à 1830. Paris: Payot, 1994. 867p.

LAROUI, Abdallah. Historia del Magreb: Desde los orígenes hasta el despertar magrebí: Un ensayo interpretativo. Madrid, MAPFRE, 1994. 423 p.

MATHIEX, Jean. Sur la Marine Marchande Barabaresque aux XVIIIe siècle. Annales E.S.C.,1958, p. 87-93.

OUTEIRO, José Maria Claro. Apontamentos sôbre o estado das pescas na área de Olhão. Lisboa: Imprensa Nacional, 1926. 57p.

RODINSON, Maxime. La Fascination de l'Islam suivi de Le seigneur bourguignon et l'esclave sarrasin. Paris: La Découverte, 1989. 200p.

STORA, Benjamin. Histoire de l'Algérie coloniale (1830-1954). Paris: La Découverte, 1991. 127p. 